\title{
Correlation between ICAM1 and VCAM1 gene polymorphisms and histopathological changes in kidney allograft biopsies
}

\author{
Leszek Domanski ${ }^{1}$, Karolina Kłoda ${ }^{1}$, Andrzej Pawlik², Magda Wisniewska ${ }^{1}$, Ewa Kwiatkowska ${ }^{1}$, \\ Mateusz Kurzawski², Krzysztof Safranow³ ${ }^{3}$ Kazimierz Ciechanowski ${ }^{1}$
}

1Department of Nephrology, Transplantology and Internal Medicine, Pomeranian Medical
University, Szczecin, Poland
2Department of Pharmacology, Pomeranian Medical University, Szczecin, Poland
3Department of Biochemistry and Medical Chemistry, Pomeranian Medical University,
Szczecin, Poland

Submitted: 26 May 2011

Accepted: 26 July 2011

Arch Med Sci 2013; 9, 2: 276-282

DOI: 10.5114 /aoms.2012.29218

Copyright @ 2013 Termedia \& Banach

\section{Abstract}

Introduction: The immunoglobulin-like molecules intercellular adhesion molecule-1 (ICAM-1) and vascular adhesion molecule-1 (VCAM-1) are responsible for endothelial cell-leukocyte adhesion followed by transmigration of leukocytes through the endothelial cell lining. The aim of this study was to examine the correlation between polymorphisms in ICAM1 and VCAM1 genes and histopathological changes in transplanted kidney biopsies.

Material and methods: The study enrolled 82 Caucasian renal transplant recipients (48 males, 34 females). Genotyping of the rs5498 ICAM1 and the rs1041163 and rs3170794 VCAM1 gene polymorphisms was performed using real-time polymerase chain reaction (PCR). Biopsies were performed in 82 patients and were reviewed by a renal pathologist and the Banff working classification criteria were used.

Results: There were no significant associations between VCAM gene polymorphisms and histopathological changes in kidney allograft biopsies. ICAM1 gene polymorphism was associated with the grade of interstitial fibrosis. Interstitial fibrosis was more severe among individuals with the $G$ allele than those with the A allele (AA vs. GG+AG, $p=0.017$ ). There were no statistically significant associations between ICAM1 gene polymorphism and other histopathological changes in kidney allograft biopsies.

Conclusions: The results of our study suggest that rs5498 ICAM1 gene polymorphism is associated with the grade of interstitial fibrosis in kidney recipients and the changes are more severe in patients with the $\mathrm{G}$ allele.

Key words: biopsy, histopathology, intercellular adhesion molecule-1, kidney allograft, polymorphism, vascular adhesion molecule-1.

\section{Introduction}

From the beginning of the 1970s kidney biopsy became the gold standard for diagnosis of its disorders. This procedure allows one not only to evaluate the morphological structure of transplanted kidney, but also to identify the ongoing processes in renal tissue and their intensification. Therefore biopsy is performed in kidney graft recipients with delayed graft function, to confirm acute rejection and to assess the degree of chronic rejec-

\author{
Corresponding author: \\ Andrzej Pawlik MD, PhD \\ Department of Pharmacology \\ Pomeranian Medical University \\ 72 Powstancow Wlkp. \\ 70-111 Szczecin, Poland \\ Phone: +48914661606 \\ E-mail: pawand@poczta.onet.pl
}


tion. Moreover, allograft biopsy is performed according to the protocol for monitoring the status of the properly functioning transplanted kidney. In 1991 in Banff (Canada) a group of scientists determined the criteria for evaluating renal kidney biopsies, allowing for standardization of the rejection process. Over the next years, during subsequent meetings, the criteria were revised, taking into account the latest discoveries in the field of clinical immunology and transplantology. Currently the Banff working classification is standard for kidney transplant pathology assessment [1-4].

Transplantation is the preferred method of treatment in established kidney failure because it prolongs the life of the patient and improves quality of life. The pathogenesis of graft rejection includes allograft tissue and endothelial injury, which are the result of immune response activation [5-7]. Cytokines and reactive oxygen species released during reperfusion increase the expression of adhesion molecules on the surface of endothelial cells [8-11]. Intercellular adhesion molecule-1 (ICAM-1, CD54, ICAM1 gene located on $19^{\text {th }}$ chromosome, locus 19p13.3p13.2) is an immunoglobulin expressed on endothelial cells, smooth muscle cells, macrophages and activated lymphocytes. Intercellular adhesion molecule-1 plays a crucial role in initiating the immunological response through the adhesion of circulating leukocytes to the blood vessel wall and transendothelial migration to tissue [12]. Vascular adhesion molecule-1 (VCAM-1, CD106, VCAM1 gene located on primer of the $1^{\text {st }}$ chromosome, locus 1p31-32) is present on the endothelium and antigen-presenting cells. This protein is an endothelial receptor for VLA4 of the $\beta 1$ subfamily of integrins and for integrin $\alpha 4 \beta 7$. Due to the interaction of these proteins, the T-cell response to alloantigens is initiated. It is significant for the early development of both acute and chronic rejection of the transplanted kidney [13]. This was confirmed in experimental studies evaluating VCAM-1 concentrations in rats undergoing renal graft chronic rejection. There was a correlation between the level of this adhesion molecule and histopathological changes in the transplanted organs. In addition, effective reduction of VCAM-1 expression in kidney allografts was linked to the reduction of the prevalence of chronic rejection [14].

Some reports suggest that ICAM-1 and VCAM-1 synthesis has a genetic background [15]. There are several polymorphisms among ICAM1 and VCAM1 genes, which are associated with changes in expression of these molecules and therefore may affect the function of the allograft and immune response after kidney transplantation. Previous studies indicated that polymorphisms rs5498:A>G in exon 6 of the ICAM1 gene, and rs3170794:T>C and rs1041163:T>C in the VCAM1 gene promoter correlated with ICAM1 and VCAM1 levels, as well as with various diseases [16-19].
The aim of this study was to examine the association between polymorphisms rs5498:A $>G$ in exon 6 of the ICAM1 gene, and rs3170794:T>C and rs1041163: T>C in the VCAM1 gene promoter and histopathological changes in transplanted kidney biopsies.

\section{Material and methods}

The study enrolled 82 consecutive Caucasian renal transplant recipients (48 males, 34 females, mean age: $47.63 \pm 12.96$ years) in whom a kidney biopsy was performed because of impaired graft function. The PAJUNK DeltaCut biopsy system was used. All biopsies were reviewed by a renal pathologist and the Banff working classification criteria were used [3]. All patients received the standard immunosuppressive protocol with triple drug therapy including a calcineurin inhibitor (cyclosporine A or tacrolimus), mycophenolate mofetil and steroids. The local ethics committee of the Pomeranian Medical University in Szczecin, Poland approved the protocol of the study.

\section{Genotyping}

Genomic DNA was extracted (precipitation with trimethyl ammonium bromide salts) from leukocytes contained in $450 \mu \mathrm{l}$ whole blood samples with ethylenediaminetetraacetic acid (EDTA) as an anticoagulant, using a non-organic and non-enzymatic extraction method. DNA was then precipitated in $99.5 \%$ ethanol and dissolved in distilled water. The range of DNA concentrations varied from $100 \mathrm{ng} / \mu \mathrm{l}$ to $500 \mathrm{ng} / \mu \mathrm{l}$. We standardized DNA with a Nanodrop ND-1000 spectrophotometer and equalized DNA concentrations to $20 \mathrm{ng} / \mu \mathrm{l}$. This material was used as a matrix for the amplification in real time polymerase chain reaction (RT-PCR). We analysed three single nucleotide polymorphisms (SNPS): rs5498:A>G in exon 6 of the ICAM1 gene, and rs3170794:T>C and rs1041163:T>C in the VCAM1 gene promoter with TaqMan probes in a 7500 Fast Real-Time PCR System machine (Applied Biosystems, USA). The substrates for the reaction were as follows: TaqMan ${ }^{\circledR}$ Genotyping Master Mix (Applied Biosystems, USA), two starters $(900 \mu \mathrm{M})$, and two TaqMan probes with 5' reporter pigment and 3' non-fluorescent quencher

Table I. Clinical characteristics of patients

\begin{tabular}{|lc|}
\hline Age years & $47.55 \pm 12.96$ \\
\hline Sex [M/F] & $48 / 34$ \\
\hline Delayed graft function & 31 patients \\
\hline Time after transplantation [months] & $31 \pm 9$ \\
\hline Creatinine [mg/dl] & $1.76 \pm 0.58$ \\
\hline Cyclosporine A [ng/ml] & $150-200$ \\
\hline Tacrolimus [ng/ml] & $7-12$ \\
\hline
\end{tabular}


Table II. Kidney allograft histopathological changes (i, t, v, ah, ci, cg, ct, cv, mm) in association with rs1041163 VCAM1 gene polymorphism

\begin{tabular}{|c|c|c|c|c|c|c|c|c|c|c|}
\hline \multirow{2}{*}{$\begin{array}{l}\text { Biopsy } \\
\text { parameter } \\
\text { and genotypes }\end{array}$} & \multicolumn{2}{|c|}{ Grade 0} & \multicolumn{2}{|c|}{ Grade 1} & \multicolumn{2}{|c|}{ Grade 2} & \multicolumn{2}{|c|}{ Grade 3} & \multirow[t]{2}{*}{ Mean \pm SD } & \multirow{2}{*}{$\begin{array}{l}M-W \text { test } p \\
\text { for comparison } \\
\text { TT vs. CC+TC }\end{array}$} \\
\hline & $n$ & $\%$ & $n$ & $\%$ & $n$ & $\%$ & $n$ & $\%$ & & \\
\hline \multicolumn{11}{|l|}{ (i) $n=72$} \\
\hline $\mathrm{TT}$ & 16 & 32.00 & 15 & 30.00 & 10 & 20.00 & 9 & 18.00 & $1.24 \pm 1.10$ & \multirow{3}{*}{0.58} \\
\hline $\mathrm{TC}$ & 3 & 15.00 & 9 & 45.00 & 4 & 20.00 & 4 & 20.00 & \multirow{2}{*}{$1.36 \pm 1.00$} & \\
\hline CC & 1 & 50.00 & 1 & 50.00 & 0 & 0.00 & 0 & 0.00 & & \\
\hline \multicolumn{11}{|l|}{ (t) $n=64$} \\
\hline TT & 13 & 30.23 & 18 & 41.86 & 8 & 18.60 & 4 & 9.30 & $1.07 \pm 0.94$ & \multirow{3}{*}{0.29} \\
\hline$T C$ & 4 & 21.05 & 8 & 42.11 & 5 & 26.32 & 2 & 10.53 & \multirow{2}{*}{$1.33 \pm 0.97$} & \\
\hline$C \mathrm{C}$ & 0 & 0.00 & 1 & 50.00 & 0 & 0.00 & 1 & 50.00 & & \\
\hline \multicolumn{11}{|l|}{ (v) $n=57$} \\
\hline $\mathrm{TT}$ & 36 & 92.31 & 2 & 5.13 & 0 & 0.00 & 1 & 2.56 & $0.13 \pm 0.52$ & \multirow{3}{*}{0.67} \\
\hline $\mathrm{TC}$ & 14 & 87.50 & 1 & 6.25 & 1 & 6.25 & 0 & 0.00 & \multirow{2}{*}{$0.17 \pm 0.51$} & \\
\hline$C \bar{C}$ & 2 & 100.0 & 0 & 0.00 & 0 & 0.00 & 0 & 0.00 & & \\
\hline \multicolumn{11}{|l|}{ (ah) $n=68$} \\
\hline $\mathrm{TT}$ & 16 & 34.78 & 23 & 50.00 & 6 & 13.04 & 1 & 2.17 & $0.83 \pm 0.74$ & \multirow{3}{*}{0.24} \\
\hline TC & 6 & 30.00 & 8 & 40.00 & 6 & 30.00 & 0 & 0.00 & \multirow{2}{*}{$1.05 \pm 0.79$} & \\
\hline$C \bar{C}$ & 0 & 0.00 & 1 & 50.00 & 1 & 50.00 & 0 & 0.00 & & \\
\hline \multicolumn{11}{|l|}{ (ci) $n=68$} \\
\hline $\mathrm{TT}$ & 25 & 54.35 & 14 & 30.43 & 5 & 10.87 & 2 & 4.35 & $0.65 \pm 0.85$ & \multirow{3}{*}{0.44} \\
\hline $\mathrm{TC}$ & 10 & 50.00 & 5 & 25.00 & 4 & 20.00 & 1 & 5.00 & \multirow{2}{*}{$0.82 \pm 0.91$} & \\
\hline$C \bar{C}$ & 0 & 0.00 & 2 & 100.0 & 0 & 0.00 & 0 & 0.00 & & \\
\hline \multicolumn{11}{|l|}{$(\mathrm{cg}) n=55$} \\
\hline $\mathrm{TT}$ & 37 & 90.24 & 3 & 7.32 & 0 & 0.00 & 1 & 2.44 & $0.15 \pm 0.53$ & \multirow{3}{*}{0.28} \\
\hline TC & 10 & 83.33 & 2 & 16.67 & 0 & 0.00 & 0 & 0.00 & \multirow{2}{*}{$0.21 \pm 0.43$} & \\
\hline$C \bar{C}$ & 1 & 50.00 & 1 & 50.00 & 0 & 0.00 & 0 & 0.00 & & \\
\hline (ct) $n=68$ & & & & & & & & & & \\
\hline $\mathrm{TT}$ & 8 & 17.39 & 24 & 52.17 & 10 & 21.74 & 4 & 8.70 & $1.22 \pm 0.84$ & \\
\hline $\mathrm{TC}$ & 2 & 10.00 & 13 & 65.00 & 3 & 15.00 & 2 & 10.00 & $122+075$ & 0.99 \\
\hline$C \bar{C}$ & 0 & 0.00 & 2 & 100.0 & 0 & 0.00 & 0 & 0.00 & 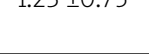 & \\
\hline (cv) $n=51$ & & & & & & & & & & \\
\hline $\mathrm{TT}$ & 24 & 66.67 & 3 & 8.33 & 4 & 11.11 & 5 & 13.89 & $0.72 \pm 1.14$ & \\
\hline TC & 6 & 46.15 & 3 & 23.08 & 1 & 7.69 & 3 & 23.08 & $107+127$ & 0.25 \\
\hline$C \bar{C}$ & 1 & 50.00 & 0 & 0.00 & 1 & 50.00 & 0 & 0.00 & $1.0 / \pm 1 . \angle 2$ & \\
\hline$(\mathrm{mm}) n=60$ & & & & & & & & & & \\
\hline TT & 25 & 59.52 & 10 & 23.81 & 1 & 2.38 & 6 & 14.29 & $0.71 \pm 1.07$ & \\
\hline $\mathrm{TC}$ & 7 & 43.75 & 4 & 25.00 & 4 & 25.00 & 1 & 6.25 & $089+096$ & 0.34 \\
\hline $\mathrm{CC}$ & 1 & 50.00 & 1 & 50.00 & 0 & 0.00 & 0 & 0.00 & $0.09 \pm .00$ & \\
\hline
\end{tabular}

$p$ value calculated with the Mann-Whitney $(M-W)$ test; $i$ - interstitial infiltration, $t$-tubulitis, $v$-intimal arteritis, ah - arteriolar hyaline thickening, ci - interstitial fibrosis, cg-glomerulopathy, ct - tubular atrophy, cv - fibrous intimal thickening, mm-mesangial matrix increase

$(200 \mu \mathrm{M})$. The probe specific for the more frequent gene allele was marked with 6-FAM reporter pigment and the probe specific for the less frequent gene allele was marked with VIC pigment. For the rs5498: A $>\mathrm{G}$ and rs3170794:T>C SNPs analysis two readymade assays were used: No. C__8726337_40 and
C 30900705_10. For the rs1041163:T>C SNP analysis we prepared a new assay with the pair of primers 5'-GAC CTC TGG GTT ACT TGT TTA TAA GCT-3', 5'-GAGATGCTGTTCTAGGGTGTGG-3' and the following probes: FAM - TAG GGA TCA GAA AAA TTG A, VIC TAG GGA TCA GAG AAA TTG $A$. The reactions were 
Table III. Kidney allograft histopathological changes (i, t, v, ah, ci, cg, ct, cv, mm) in association with rs3170794 VCAM1 gene polymorphism

\begin{tabular}{|c|c|c|c|c|c|c|c|c|c|c|}
\hline \multirow{2}{*}{$\begin{array}{l}\text { Biopsy } \\
\text { parameter } \\
\text { and genotypes }\end{array}$} & \multicolumn{2}{|c|}{ Grade 0} & \multicolumn{2}{|c|}{ Grade 1} & \multicolumn{2}{|c|}{ Grade 2} & \multicolumn{2}{|c|}{ Grade 3} & \multirow[t]{2}{*}{ Mean \pm SD } & \multirow{2}{*}{$\begin{array}{l}M-\mathrm{W} \text { test } p \\
\text { for comparison } \\
\text { TC vs. TT }\end{array}$} \\
\hline & $n$ & $\%$ & $n$ & $\%$ & $n$ & $\%$ & $n$ & $\%$ & & \\
\hline \multicolumn{11}{|l|}{ (i) $n=72$} \\
\hline TT & 19 & 27.54 & 24 & 34.78 & 14 & 20.29 & 12 & 17.39 & $1.28 \pm 1.06$ & \multirow[t]{2}{*}{1.00} \\
\hline $\mathrm{TC}$ & 1 & 33.33 & 1 & 33.33 & 0 & 0.00 & 1 & 33.33 & $1.33 \pm 1.53$ & \\
\hline \multicolumn{11}{|l|}{ (t) $n=64$} \\
\hline $\mathrm{TT}$ & 17 & 27.87 & 25 & 40.98 & 13 & 21.31 & 6 & 9.84 & $1.13 \pm 0.94$ & \multirow[t]{2}{*}{0.39} \\
\hline $\mathrm{TC}$ & 0 & 0.00 & 2 & 66.67 & 0 & 0.00 & 1 & 33.33 & $1.67 \pm 1.15$ & \\
\hline \multicolumn{11}{|l|}{ (v) $n=57$} \\
\hline TT & 51 & 91.07 & 3 & 5.36 & 1 & 1.79 & 1 & 1.79 & $0.14 \pm 0.52$ & \multirow[t]{2}{*}{1.00} \\
\hline $\mathrm{TC}$ & 1 & 100.0 & 0 & 0.00 & 0 & 0.00 & 0 & 0.00 & - & \\
\hline \multicolumn{11}{|l|}{ (ah) $n=68$} \\
\hline $\mathrm{TT}$ & 21 & 31.82 & 31 & 46.97 & 13 & 19.70 & 1 & 1.52 & $0.91 \pm 0.76$ & \multirow[t]{2}{*}{0.46} \\
\hline $\mathrm{TC}$ & 1 & 50.00 & 1 & 50.00 & 0 & 0.00 & 0 & 0.00 & $0.50 \pm 0.71$ & \\
\hline \multicolumn{11}{|l|}{ (ci) $n=68$} \\
\hline $\mathrm{TT}$ & 33 & 50.77 & 20 & 30.77 & 9 & 13.85 & 3 & 4.62 & $0.72 \pm 0.88$ & \multirow[t]{2}{*}{0.48} \\
\hline $\mathrm{TC}$ & 2 & 66.67 & 1 & 33.33 & 0 & 0.00 & 0 & 0.00 & $0.33 \pm 0.58$ & \\
\hline \multicolumn{11}{|l|}{ (cg) $n=55$} \\
\hline $\mathrm{TT}$ & 47 & 87.04 & 6 & 11.11 & 0 & 0.00 & 1 & 1.85 & $0.17 \pm 0.50$ & \multirow[t]{2}{*}{1.00} \\
\hline $\mathrm{TC}$ & 1 & 100.0 & 0 & 0.00 & 0 & 0.00 & 0 & 0.00 & - & \\
\hline \multicolumn{11}{|l|}{ (ct) $n=68$} \\
\hline TT & 9 & 13.85 & 37 & 56.92 & 13 & 20.00 & 6 & 9.23 & $1.25 \pm 0.81$ & \multirow[t]{2}{*}{0.20} \\
\hline $\mathrm{TC}$ & 1 & 33.33 & 2 & 66.67 & 0 & 0.00 & 0 & 0.00 & $0.67 \pm 0.58$ & \\
\hline \multicolumn{11}{|l|}{ (cv) $n=51$} \\
\hline $\mathrm{TT}$ & 29 & 60.42 & 6 & 12.50 & 6 & 12.50 & 7 & 14.58 & $0.81 \pm 1.14$ & \multirow[t]{2}{*}{0.95} \\
\hline $\mathrm{TC}$ & 2 & 66.67 & 0 & 0.00 & 0 & 0.00 & 1 & 33.33 & $1.00 \pm 1.73$ & \\
\hline \multicolumn{11}{|l|}{$(\mathrm{mm}) n=60$} \\
\hline TT & 32 & 55.17 & 14 & 24.14 & 5 & 8.62 & 7 & 12.07 & $0.78 \pm 1.04$ & \multirow[t]{2}{*}{0.89} \\
\hline $\mathrm{TC}$ & 1 & 50.00 & 1 & 50.00 & 0 & 0.00 & 0 & 0.00 & $0.50 \pm 0.71$ & \\
\hline
\end{tabular}

$p$ value calculated with the Mann-Whitney $(M-W)$ test; $i$ - interstitial infiltration, $t$ - tubulitis, $v$ - intimal arteritis, ah - arteriolar hyaline thickening, ci-interstitial fibrosis, cg-glomerulopathy, ct-tubular atrophy, cv-fibrous intimal thickening, mm-mesangial matrix increase

performed at $95^{\circ} \mathrm{C}$ for 10 min due to AmpliTaq Gold polymerase activation, then 40 cycles of $15 \mathrm{~s}$ at $92^{\circ} \mathrm{C}$ and $60 \mathrm{~s}$ at $60^{\circ} \mathrm{C}$. The genotypes were determined automatically through the comparison of 6-FAM and $\mathrm{VIC}$ pigment fluorescence. Then the results were verified in the review of the amplification plot curves.

\section{Statistical analysis}

The association of histopathological changes in renal grafts with genotypes was analysed with Mann-Whitney test. Value of $p$ below 0.05 was considered as statistically significant.

\section{Results}

The clinical characteristic of patients are presented in Table I. As shown in Tables II and III, there were no significant associations between VCAM gene polymorphisms and histopathological changes in kidney allograft biopsies.

With regard to the ICAM1 gene polymorphism, there was a significant association with the grade of interstitial fibrosis. Interstitial fibrosis was more severe among individuals with the $G$ allele than those with the $A$ allele (AA vs $G G+A G, p=0.017$ ) (Table IV). Moreover, mesangial matrix increase was more enhanced among individuals with the ICAM1 G allele than among those with the A allele (AA vs. GG+AG, $p=0.06$ ) (Table II). These differences were on the border of statistical significance. There were no statistically significant associations between ICAM1 gene polymorphism and other histopathological changes in kidney allograft biopsies.

Additionally we analysed the creatinine concentrations in association with studied polymorphisms. 
Table IV. Kidney allograft histopathological changes (i, t, v, ah, ci, cg, ct, cv, mm) in association with rs5498 ICAM1 gene polymorphism

\begin{tabular}{|c|c|c|c|c|c|c|c|c|c|c|}
\hline \multirow{2}{*}{$\begin{array}{l}\text { Biopsy } \\
\text { parameter } \\
\text { and genotypes }\end{array}$} & \multicolumn{2}{|c|}{ Grade 0} & \multicolumn{2}{|c|}{ Grade 1} & \multicolumn{2}{|c|}{ Grade 2} & \multicolumn{2}{|c|}{ Grade 3} & \multirow[t]{2}{*}{ Mean \pm SD } & \multirow{2}{*}{$\begin{array}{c}M-W \text { test } p \\
\text { for comparison } \\
\text { AA vs. GG+AG }\end{array}$} \\
\hline & $n$ & $\%$ & $n$ & $\%$ & $n$ & $\%$ & $n$ & $\%$ & & \\
\hline \multicolumn{11}{|l|}{ (i) $n=72$} \\
\hline AA & 8 & 33.33 & 8 & 33.33 & 4 & 16.67 & 4 & 16.67 & $1.17 \pm 1.09$ & \multirow{3}{*}{0.50} \\
\hline$A \bar{G}$ & 9 & 27.27 & 11 & 33.33 & 7 & 21.21 & 6 & 18.18 & $1.30 \pm 1.07$ & \\
\hline$G \bar{G}$ & 3 & 20.00 & 6 & 40.00 & 3 & 20.00 & 3 & 20.00 & $1.40 \pm 1.06$ & \\
\hline \multicolumn{11}{|l|}{ (t) $n=64$} \\
\hline AA & 6 & 27.27 & 9 & 40.91 & 4 & 18.18 & 3 & 13.64 & $1.18 \pm 1.00$ & \multirow{3}{*}{0.94} \\
\hline$A G$ & 9 & 33.33 & 10 & 37.04 & 7 & 25.93 & 1 & 3.70 & $1.00 \pm 0.88$ & \\
\hline $\mathrm{GG}$ & 2 & 13.33 & 8 & 53.33 & 2 & 13.33 & 3 & 20.00 & $1.40 \pm 0.99$ & \\
\hline \multicolumn{11}{|l|}{ (v) $n=57$} \\
\hline AA & 18 & 90.00 & 1 & 5.00 & 0 & 0.00 & 1 & 5.00 & $0.20 \pm 0.70$ & \multirow{3}{*}{0.79} \\
\hline$A \bar{G}$ & 25 & 96.15 & 0 & 0.00 & 1 & 3.85 & 0 & 0.00 & $0.08 \pm 0.39$ & \\
\hline$G \bar{G}$ & 9 & 81.82 & 2 & 18.18 & 0 & 0.00 & 0 & 0.00 & $0.18 \pm 0.40$ & \\
\hline \multicolumn{11}{|l|}{ (ah) $n=68$} \\
\hline AA & 9 & 40.91 & 10 & 45.45 & 3 & 13.64 & 0 & 0.00 & $0.73 \pm 0.70$ & \multirow{3}{*}{0.21} \\
\hline$A \bar{G}$ & 7 & 20.59 & 17 & 50.00 & 10 & 29.41 & 0 & 0.00 & $1.09 \pm 0.71$ & \\
\hline $\mathrm{GG}$ & 6 & 50.00 & 5 & 41.67 & 0 & 0.00 & 1 & 8.33 & $0.67 \pm 0.89$ & \\
\hline \multicolumn{11}{|l|}{ (ci) $n=68$} \\
\hline AA & 16 & 69.57 & 6 & 26.09 & 1 & 4.35 & 0 & 0.00 & $0.35 \pm 0.57$ & \multirow{3}{*}{0.017} \\
\hline$A \bar{G}$ & 12 & 37.50 & 13 & 40.63 & 5 & 15.63 & 2 & 6.25 & $0.91 \pm 0.89$ & \\
\hline$G \bar{G}$ & 7 & 53.85 & 2 & 15.38 & 3 & 23.08 & 1 & 7.69 & $0.85 \pm 1.07$ & \\
\hline \multicolumn{11}{|l|}{ (cg) $n=55$} \\
\hline AA & 15 & 100.0 & 0 & 0.00 & 0 & 0.00 & 0 & 0.00 & $0.00 \pm 0.00$ & \multirow{3}{*}{0.086} \\
\hline$A \bar{G}$ & 23 & 79.31 & 5 & 17.24 & 0 & 0.00 & 1 & 3.45 & $0.28 \pm 0.65$ & \\
\hline GG & 10 & 90.91 & 1 & 9.09 & 0 & 0.00 & 0 & 0.00 & $0.09 \pm 0.30$ & \\
\hline \multicolumn{11}{|l|}{ (ct) $n=68$} \\
\hline AA & 4 & 17.39 & 15 & 65.22 & 4 & 17.39 & 0 & 0.00 & $1.00 \pm 0.60$ & \multirow{3}{*}{0.16} \\
\hline$A \bar{G}$ & 2 & 6.06 & 20 & 60.61 & 6 & 18.18 & 5 & 15.15 & $1.42 \pm 0.83$ & \\
\hline $\mathrm{GG}$ & 4 & 33.33 & 4 & 33.33 & 3 & 25.00 & 1 & 8.33 & $1.08 \pm 1.00$ & \\
\hline \multicolumn{11}{|l|}{ (cv) $n=51$} \\
\hline $\mathrm{AA}$ & 8 & 53.33 & 1 & 6.67 & 3 & 20.00 & 3 & 20.00 & $1.07 \pm 1.28$ & \multirow{3}{*}{0.39} \\
\hline$A \bar{G}$ & 18 & 69.23 & 3 & 11.54 & 3 & 11.54 & 2 & 7.69 & $0.58 \pm 0.99$ & \\
\hline$G \bar{G}$ & 5 & 50.00 & 2 & 20.00 & 0 & 0.00 & 3 & 30.00 & $1.10 \pm 1.37$ & \\
\hline \multicolumn{11}{|l|}{$(\mathrm{mm}) n=60$} \\
\hline AA & 13 & 76.47 & 2 & 11.76 & 0 & 0.00 & 2 & 11.76 & $0.47 \pm 1.00$ & \multirow{3}{*}{0.065} \\
\hline$A \bar{G}$ & 13 & 41.49 & 12 & 38.71 & 4 & 12.90 & 2 & 6.45 & $0.84 \pm 0.90$ & \\
\hline $\mathrm{GG}$ & 7 & 58.33 & 1 & 8.33 & 1 & 8.33 & 3 & 25.00 & $1.00 \pm 1.35$ & \\
\hline
\end{tabular}

$p$ value calculated with the Mann-Whitney $(M-W)$ test; $i$ - interstitial infiltration, $t$-tubulitis, $v$-intimal arteritis, ah - arteriolar hyaline thickening, ci-interstitial fibrosis, cg-glomerulopathy, ct - tubular atrophy, cv-fibrous intimal thickening, mm-mesangial matrix increase

ICAM1 rs5498 GG genotype was associated with increased creatinine concentrations $(1.96 \pm 0.56$ $\mathrm{mg} / \mathrm{dl})$ in comparison with $\mathrm{AG}(1.72 \pm 0.66 \mathrm{mg} / \mathrm{dl})$ and AA genotypes $(1.69 \pm 0.51 \mathrm{mg} / \mathrm{dl})(\mathrm{AA}+\mathrm{AG} \mathrm{vs}$. GG, $p=0.004)$. There were no statistically significant associations between VCAM gene polymorphisms and creatinine concentrations.

\section{Discussion}

In our study we examined the association between polymorphisms in ICAM1 and VCAM1 genes and histopathological changes in transplanted kidney biopsies. We observed a statistically significant association between the grade of interstitial fibrosis 
and rs5498 ICAM1 gene polymorphism. Histopathological lesions were more severe among $G$ allele carriers than among those with the A allele.

Intercellular adhesion molecule-1 is an adhesion receptor and is found on leukocytes and endothelial cells [20]. Increased expression of ICAM-1 has been found in biopsies of renal allograft with rejection [21]. Previous reports have shown the presence of VCAM-1 on parietal cells lining Bowman's capsule $[22,23]$. In kidney allografts with rejection the increased expression of VCAM-1 was observed in muscular artery endothelium and in smooth muscle cells. It has been postulated that the upregulation of both ICAM-1 and VCAM-1 could facilitate the destruction of capillaries and tubular cells in kidney rejection $[24,25]$.

Adhesion molecules may mediate the infiltration process, but may also serve as a costimulatory signal for T-cell activation by antigen-presenting cells. Previous studies examined the expression of adhesion molecules in inflammatory renal diseases and revealed increased expression of adhesion molecules in biopsies with chronic histological damage. Increased expression of ICAM-1 and VCAM-1 was observed in different renal diseases and correlated with structural tubular damage and interstitial fibrosis [26].

In recent years, the frequency of acute rejection episodes after kidney transplantation has been decreasing, but interstitial fibrosis and tubular atrophy are still the main cause of kidney function loss. Infiltration of inflammatory cells into the allograft interstitium is the basis of the alloimmune response that leads to injury and subsequent interstitial fibrosis and chronic allograft failure [27]. Clinical factors that are correlated with interstitial fibrosis include older recipient age, greater human leukocyte antigen (HLA) mismatch and the use of calcineurin inhibitors [28, 29]. Kwiatkowski et al. described changes in allograft biopsies which where associated with preservation method during cold ischaemia time. Interstitial fibrosis and tubular atrophy were diagnosed more often in hypothermically stored allografts. Moreover, there was a higher frequency of interstitial fibrosis [30]. Heilman et al. analysed histopathological changes in allografts among patients with the steroid withdrawal protocol. Biopsies were performed during the reperfusion, and in the $1^{\text {st }}, 4^{\text {th }}$ and $12^{\text {th }}$ month after transplantation. Interstitial fibrosis was diagnosed in 19\% of kidney recipients 1 year after transplantation. It was shown that increased creatinine serum concentrations and recipient's age were the risk factors of interstitial fibrosis [31]. Servais et al. examined the effect of cyclosporine to sirolimus conversion on interstitial fibrosis. Biopsy results revealed no differences between cyclosporine and sirolimus treated patients in the percentage of interstitial fibrosis [32]. In another study the authors evaluated the genes associated with the onset of interstitial fibrosis and tubular atrophy. The 3-month biopsies of the kidneys with interstitial fibrosis and tubular atrophy showed overexpression of several genes that are important in T- and B-cell activation and the immune response and are involved in profibrotic processes. Furthermore, several genes with transporter and metabolic functions were underrepresented in these biopsies. The authors conclude that interstitial fibrosis and tubular atrophy occur already before they are detectable with conventional histopathological examination of renal allografts. Thus, microarray technology applied to protocol biopsies provides insight into the pathophysiology of these processes and might allow for a more timely therapeutic intervention [33].

In conclusion, the results of our study suggest that rs5498 ICAM1 gene polymorphism is associated with the grade of interstitial fibrosis in kidney allograft recipients and the changes are more severe in patients with the $G$ allele.

\section{References}

1. Solez K, Axelsen RA, Benediktsson H, et al. International standardization of criteria for the histologic diagnosis of renal allograft rejection: the Banff working classification of kidney transplant pathology. Kidney Int 1993; 44: 411-22.

2. Racusen LC, Solez K, Colvin RB, et al. The Banff 97 working classification of renal allograft pathology. Kidney Int 1999; 55: 713-23.

3. Solez K, Colvin RB, Racusen LC, et al. Banff 07 classification of renal allograft pathology: updates and future directions. Am J Transplant 2008; 8: 753-60.

4. Solez K. History of the Banff classification of allograft pathology as it approaches its 20th year. Curr Opin Organ Transplant 2010; 15: 49-51.

5. Lubas A, Żelichowski G, Próchnicka A, Wiśniewska M, Saracen M, Wańkowicz Z. Renal vascular response to angiotensin II inhibition in intensive antihypertensive treatment of essential hypertension. Arch Med Sci 2010; 6: 533-8.

6. Malyszko J, Zbroch E, Malyszko J, Mysliwiec M, laina A. The cardio-renal-anaemia syndrome predicts survival in peritoneally dialyzed patients. Arch Med Sci 2010; 6: 539-44.

7. Shouman M, Abdallah N, El Tablawy N, Rashed L. Biochemical markers of endothelial dysfunction in pediatric nephrotic syndrome. Arch Med Sci 2009; 5: 415-21.

8. Haleagrahara N, Yee T, Chakravarthi S, Lee N. Protective effect of $\mathrm{N}$-acetylcysteine on cyclosporine A-induced changes in lipid hydroperoxide levels and renal dysfunction in rats. Arch Med Sci 2009; 5: 16-22.

9. Yu M, Wen N, Wenzhong Z, Yuanchang X, Xiaoming D, Yongjin L. Effect of repeated ischaemic preconditioning on TLR4 and proinflammatory cytokines TNF-alpha and IL-1beta in myocardial ischaemia-reperfusion injury in a rat model. Arch Med Sci 2010; 6: 843-7.

10. Ysebaert DK, De Greef KE, Vercauteren SR, et al. Identification and kinetics of leukocytes after severe ischaemia/reperfusion renal injury. Nephrol Dial Transplant 2000; 15: 1562-74.

11. Kim I, Moon SO, Kim SH, Kim HJ, Koh YS, Koh GY. Vascular endothelial growth factor expression of intercellular adhesion molecule 1 (ICAM-1), vascular cell adhesion molecule 1 (VCAM-1), and E-selectin through nuclear factor-kappa B activation in endothelial cells. J Biol Chem 2001; 276: 7614-20. 
12. Rabb H, Bonventre JV. Leukocyte adhesion molecules in transplantation. Am J Med 1999; 107: 157-65.

13. Jeong HJ, Lee HH, Kim YS, Kim SI, Moon J, Park K. Expression of ICAM-1 and VCAM-1 in renal allograft rejection. Transplant Proc 1998; 30: 2953-4.

14. Crews GM, Erickson L, Pan F, et al. Down-regulation of TGF-beta and VCAM-1 is associated with successful treatment of chronic rejection in rats. Transplant Proc 2005; 37: 1926-8.

15. Akalin E, Murphy B. Gene polymorphisms and transplantation. Curr Opin Immunol 2001; 13: 572-6.

16. Bielinski SJ, Pankow JS, Li N, et al. ICAM1 and VCAM1 polymorphisms, coronary artery calcium, and circulating levels of soluble ICAM-1: the multi-ethnic study of atherosclerosis (MESA). Atherosclerosis 2008; 201: 339-44.

17. Abel M, Cellier C, Kumar N, Cerf-Bensussan N, Schmitz J, Caillat-Zucman S. Adulthood-onset celiac disease is associated with intercellular adhesion molecule-1 (ICAM-1) gene polymorphism. Hum Immunol 2006; 67: 612-7.

18. Gbadegesin RA, Cotton SA, Watson CJ, Brenchley PE, Webb NJ. Association between ICAM-1 Gly-Arg polymorphism and renal parenchymal scarring following childhood urinary tract infection. Int J Immunogenet 2006; 33: 49-53.

19. Sarecka-Hujar B, Zak I, Krauze J. Interactions between rs5498 polymorphism in the ICAM1 gene and traditional risk factors influence susceptibility to coronary artery disease. Clin Exp Med 2009; 9: 117-24.

20. Lahiri DK, Bye S, Nurnberger JI Jr, Hodes ME, Crisp M. A non-organic and non-enzymatic extraction method gives higher yields of genomic DNA from whole-blood samples than do nine other methods tested. J Biochem Biophys Methods 1992; 25: 193-205.

21. Bishop GA, Hall BM. Expression of leucocyte and lymphocyte adhesion molecules in the human kidney. Kidney Int 1989; 36: 1078-85.

22. Faull RJ, Russ GR. Tubular expression of intercellular adhesion molecule-1 during renal allograft rejection. Transplantation 1989; 48: 226-30.

23. Seron D, Cameron JS, Haskard DO. Expression of VCAM1 in the normal and diseased kidney. Nephrol Dial Transplant 1991; 6: 917-22.

24. Alpers CE, Hudkins KL, Davis CL, et al. Expression of vascular cell adhesion molecule-1 in kidney allograft rejection. Kidney Int 1993; 44: 805-16.

25. Brockmeyer C, Ulbrecht M, Schendel DJ, et al. Distribution of cell adhesion molecules (ICAM-1, VCAM-1, ELAM-1) in renal tissue during allograft rejection. Transplantation 1993; 55: 610-5.

26. Mampaso F, Sanchez-Madrid F, Marcen R, et al. Expression of adhesion molecules in allograft renal dysfunction. A distinct diagnostic pattern in rejection and cyclosporine nephrotoxicity. Transplantation 1993; 56: 687-91.

27. Mrowka C, Sieberth HG. Detection of circulating adhesion molecules ICAM-1, VCAM-1 and E-selectin in Wegener's granulomatosis, systemic lupus erythematosus and chronic renal failure. Clin Nephrol 1995; 43: 288-96.

28. Nankivell BJ, Borrows RJ, Fung CL, O’Connell PJ, Chapman JR, Allen RD. Delta analysis of posttransplantation tubu lointerstitial damage. Transplantation 2004; 78: 434-41.

29. Cosio FG, Grande JP, Larson TS, et al. Kidney allograft fibrosis and atrophy early after living donor transplantation. Am J Transplant 2005; 5: 1130-6.

30. Kwiatkowski A, Wszoła M, Perkowska-Ptasińska A, et al. Influence of preservation method on histopathological lesions of kidney allografts. Ann Transplant 2009; 14: 10-3.

31. Heilman RL, Chakkera HA, Reddy KS, et al. Clinical factors associated with graft fibrosis in kidney-transplant recipi- ents on steroid-avoidance immunosuppression. Clin Transplant 2008; 22: 309-15.

32. Servais A, Meas-Yedid V, Toupance O, et al. Interstitial fibrosis quantification in renal transplant recipients randomized to continue cyclosporine or convert to sirolimus. Am J Transplant 2009; 9: 2552-60.

33. Scherer A, Gwinner W, Mengel M, et al. Transcriptome changes in renal allograft protocol biopsies at 3 months precede the onset of interstitial fibrosis/tubular atrophy (IF/TA) at 6 months. Nephrol Dial Transplant 2009; 24 2567-75. 